Proc. Indian Acad. Sci. (Chem. Sci.), Vol. 105, No. 6, December 1993, pp. 735-746.

(C) Printed in India.

\title{
Laser degradation of pollutants: Polychlorobiphenyls, triazines and polycyclic aromatic hydrocarbons
}

\author{
R FANTONI ${ }^{1}$, A GIARDINI-GUIDONI, A MELE*, \\ G PIZZELLA and R TEGHIL ${ }^{2}$ \\ Dipartimento di Chimica, Università "La Sapienza," P le A Moro 5, Rome, Italy \\ ${ }^{1}$ ENEA, AREA INN, Dip. SVIL ÇP 65, Frascati, Italy \\ ${ }^{2}$ Dipartimento di Chimica, Università di Basilicata, Via N. Sauro 85, Potenza, Italy
}

\begin{abstract}
Visible and UV radiations have been widely used to induce chemical reactions in gases, liquids and heterogeneous systems before the development of commercial lasers for use in these regions. The availability of laser sources has allowed extensive studies on chemical reactions and time-resolved techniques to investigate the mechanism of excitation and relaxation of organic molecules in gaseous and condensed phases.

A very important field recently investigated is the laser-induced decomposition of organic molecules, present either as gas or as major constituents of or traces in solutions, with the aim of removing toxic species from chemically hazardous wastes. An investigation of laserinduced decomposition of important categories of pollutants such as polychlorobiphenyls, herbicides (triazines) and polycyclic aromatic hydrocarbons will be reported here. The experiments demonstrate the effectiveness of laser-induced techniques for the decomposition of these compounds. In most cases photofragmentation leads to the formation of non-toxic products in very high yields.
\end{abstract}

Keywords. Laser; degradation; ablation; polychlorobiphenyl; triazine; polycyclic aromatic hydrocarbons.

\section{Introduction}

In the past years there has been a very strong interest in developing new technologies to monitor the environment and to reduce the level of pollutants. Different types of laser sources ranging from IR to UV have been employed to induce reactions in gases, liquids and heterogeneous systems. Degradation of organic pollutants has also been studied to determine the various products obtained by irradiation and to establish the mechanism of the dissociation process. Chemical reactors equipped for irradiation of solid, liquid and gas phase systems have been built. On-line diagnostic techniques such as laser-induced fluorescence (LIF), coherent antistokes Raman scattering (CARS), luminescence and time-of-flight (TOF) mass spectrometry have been developed and utilized to detect transient reaction intermediates. Final products have been analysed by gas chromatography, HPLC and XPS spectroscopy.

This report will deal with an experimental investigation on the laser-induced degradation of three important pollutants, namely polychlorobiphenyls (PCB),

${ }^{*}$ For correspondence 
herbicides (triazines) and polycyclic aromatic hydrocarbons (PAH). The aim of these studies was to obtain a quantitative laser-induced decomposition of these compounds by employing radiation from different lasers. Excimer lasers $(\lambda=308,248$ and $193 \mathrm{~nm})$, frequency quadrupled Nd-YAG laser $(\lambda=266 \mathrm{~nm})$, were utilized to remove these toxic products and to establish the condition for drastically reducing chemical hazards, so that the harmless wastes can be either reused or released without danger to the environment.

\section{Polychlorobiphenyls}

The molecular structures of all PCB are similar to that of diphenyl, which is known to be formed by two phenyl rings lying in $45^{\circ}$ rotated planes. Because of partial conjugation between the two aromatic $\pi$ systems, the biphenyl molecules show a fairly strong $\pi \rightarrow \pi^{*}$ UV absorption peaked at $249 \mathrm{~nm}$ (Dyke et al 1971).

The occurrence of UV absorption resonant with available excimer laser radiation suggested the PCB photodecomposition experiments here reported. The laser irradiation of PCBs in the liquid phase was performed by excimer lasers at 308, 248 and $193 \mathrm{~nm}$ with a pulse length of $10-15 \mathrm{~ns}$ according to the laser mixture and total pressure. A commercial mixture of PCBs (Aroclor 1254) in $n$-hexane and in methanol were used.

Quantitative analyses of the irradiated products were carried out by means of gas-liquid chromatography. The chromatograph had both pulsed electron capture detector and flame ionization detector capabilities. It is worth recalling that the electron capture detector (ECD) is sensitive only to electronegative atoms, mostly to chlorine and other halogens and less to oxygen. The flame ionization detector (FID) counts all the positive ions generated in the combustion of the organic molecule, i.e. it registers peaks due to non-substituted hydrocarbons.

The energetics of the bond-breaking processes (Guggenheim and Prue 1964) which correlate to the energy of the excimer lasers employed, strongly supports single-photon absorption for direct dissociation of PCB. In fact the $\mathrm{XeCl}$ laser should induce only dechlorination on some heavy PCB, whereas the KrF laser is expected to break the biphenyl bond; the complete rupture of all the aromatic rings could be achieved by the ArF laser provided that all congeners in the mixtures absorb this radiation. Irradiation of $250 \mu \mathrm{g} / \mathrm{ml}$ of Aroclor $1254 \mathrm{in} n$-hexane $(1 \mathrm{~h}, 2 \mathrm{~Hz})$ using the $\mathrm{XeCl}(75 \mathrm{~mJ})$, $\mathrm{KrF}(40 \mathrm{~mJ})$ and $\mathrm{ArF}(4 \mathrm{~mJ})$ lasers have fully confirmed these simple predictions. As expected, after $\mathrm{XeCl}$ laser irradiation the gas chromatographic analysis (ECD detector) showed the occurrence of dechlorination and isomerization with disappearance of a few heavy PCB and the formation of lighter homologues. Neither the effective destruction of the pollutant or complete dechlorination was acheved due to the fact that not all the PCB in the Aroclor 1254 mixture contribute to the UV absorption band at $320 \mathrm{~nm}$. Much lighter species, corresponding to biphenyl and aromatic bond rupture were produced by irradiation with the ArF laser. Nevertheless only some of the heavy PCB congeners were dissociated and the process was ineffective for the destruction of the whole family of pollutants. This should be related to the bad matching between the laser emission wavelength and the overall absorption spectrum of the mixture. Complete destruction of the PCB was observed after irradiation of the Aroclor 1254 with $\mathrm{KrF}$ accompanied by the formation of light hydrocarbons.

The data in figure 1 show that all PCB in Aroclor 1254 have been completely destroyed and no chlorinated or oxidized products are formed. The data in figure 2 


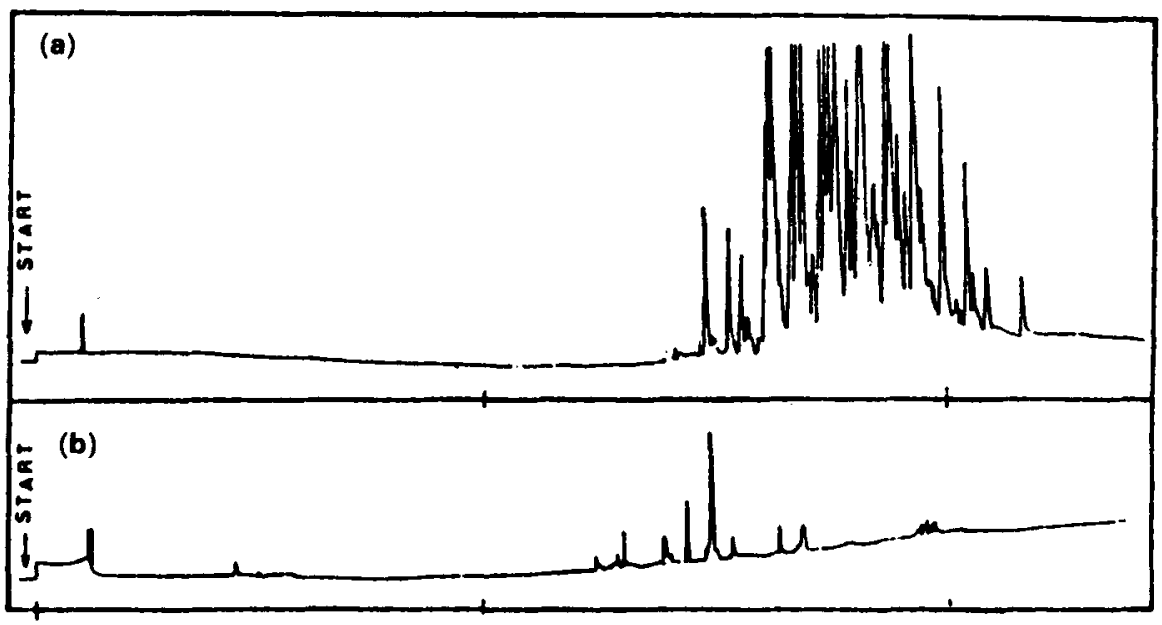

Figure 1. Gas chromatograms of $187 \mu \mathrm{g} / \mathrm{ml}$ Aroclor 1254 in $n$-hexane, measured using an FID detector: (a) before irradiation, (b) after irradiation with a $\mathrm{KrF}$ laser at the same conditions as above.

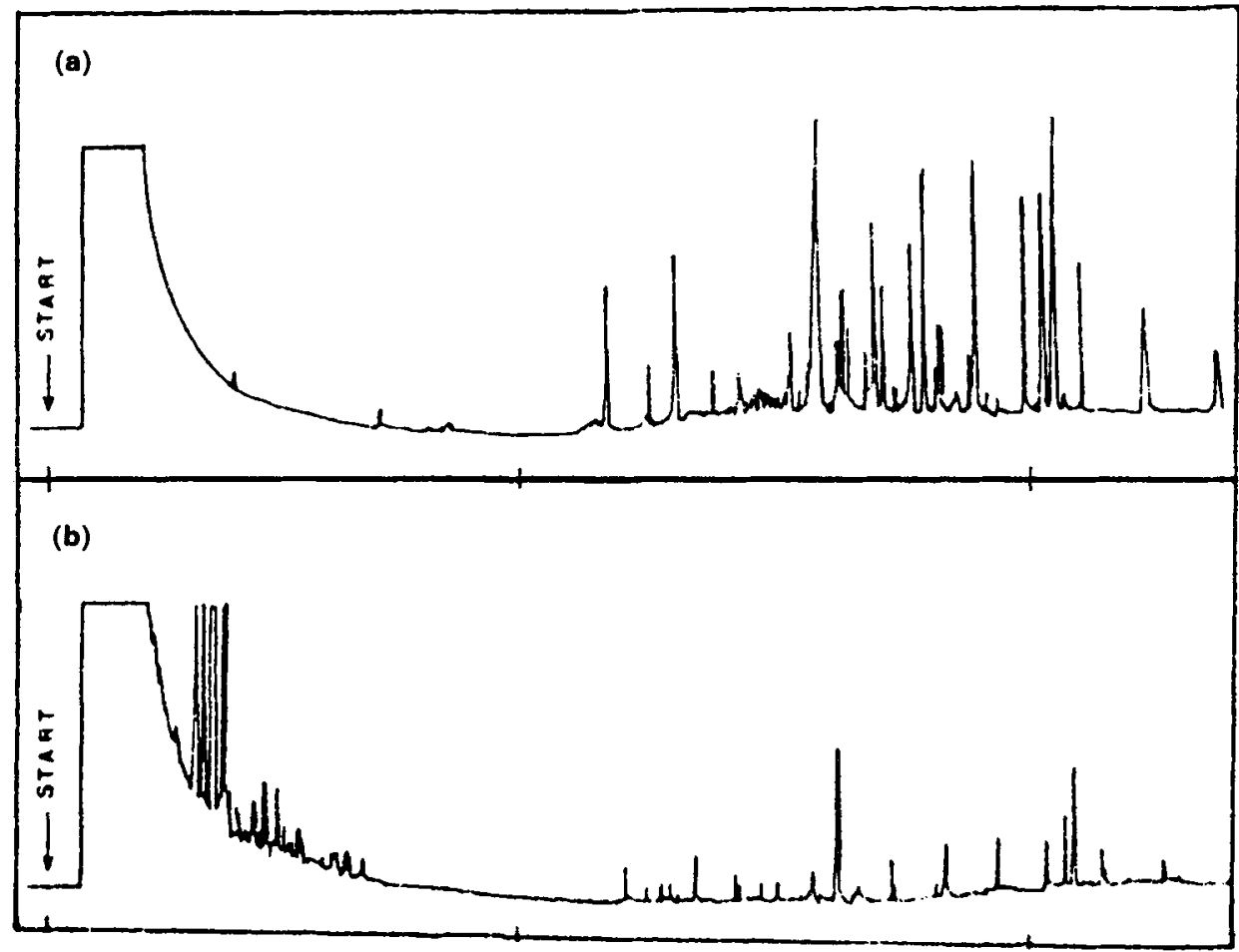

Figure 2. Gas chromatograms of $187 \mu \mathrm{g} / \mathrm{ml}$ Aroclor 1254 in $n$-hexane, measured using ECD detector: (a) before irradiation, (b) after $60 \mathrm{~min}$ of irradiation, $40 \mathrm{~mJ} \mathrm{KrF}$ laser at $2 \mathrm{~Hz}$.

confirm the complete PCB destruction, only traces of heavy species are detected which appear to correspond to molecules containing condensed aromatic rings. Since $\mathrm{C}-\mathrm{H}$ bond rupture is the second threshold for PCB dissociation and it is also accessible energetically, $\mathrm{HCl}$ should be the main chlorinated product. $\mathrm{HCl}$ traces were indeed 
found in the solution containing the final products after extraction with distilled water and ion chromatography.

\section{Polycyclic aromatic hydrocarbons}

It is well known that many noxious organic compounds found in the ambient particulate originate from anthropogenic sources (Hrudey et al 1974). The attention in environmental research has been focussed on polycyclic aromatic hydrocarbons (PAH), which have strong carcinogenic action. Recently, PAH have been identified in the fly ash from municipal incinerators together with polychlorodibenzo-p-dioxins (PCDDS) and polychlorodibenzofurans (PCDF) which are formed by pyrolysis of polychlorobenzenes (PCBz) and polychlorophenols (PCP) (Buser 1979).

The investigation of the ablative photodecomposition of these organic materials has been performed with both a pulsed TEA $\mathrm{CO}_{2}$ laser and a frequency quadrupled Nd-YAG laser. Ablation by a $\mathrm{CO}_{2}$ laser operating on the $10 \mu \mathrm{P} 20$ line was performed on a solid target irradiated at normal incidence. The ablated material originates a luminous plume of $1 \mathrm{~cm}$ height. Emission has been collected and qualitatively analysed as a function of wavelength by an optical multichannel analyser system (OMA). The laser-ablated solid was deposited on a substrate and analysed by ESCA. ESCA analysis of the thin film resulting from anthracene ablation is reported in figure 3 for the $\mathrm{C}_{s}$ region. It can be seen that it qualitatively corresponds to the graphite peak confirming that most of the ablated anthracene gives rise to carbon. The spectral analysis of the plume by OMA shows that emission is mainly due to hydrogen and the minor peaks are assigned to $\mathrm{C}^{+}, \mathrm{C}_{2}, \mathrm{C}_{3}$ as reported in figure 4 . These results, indicate that the energy deposited in the solid by the laser initiates a process which leads to total degradation and graphitisation of the pollutant.

Ions resulting from the ablation process by means of the Nd:YAG laser were analysed by a time-of-flight mass spectrometer. Both positive and negative ions have been detected and mass analysed. One striking feature of the abundances for both

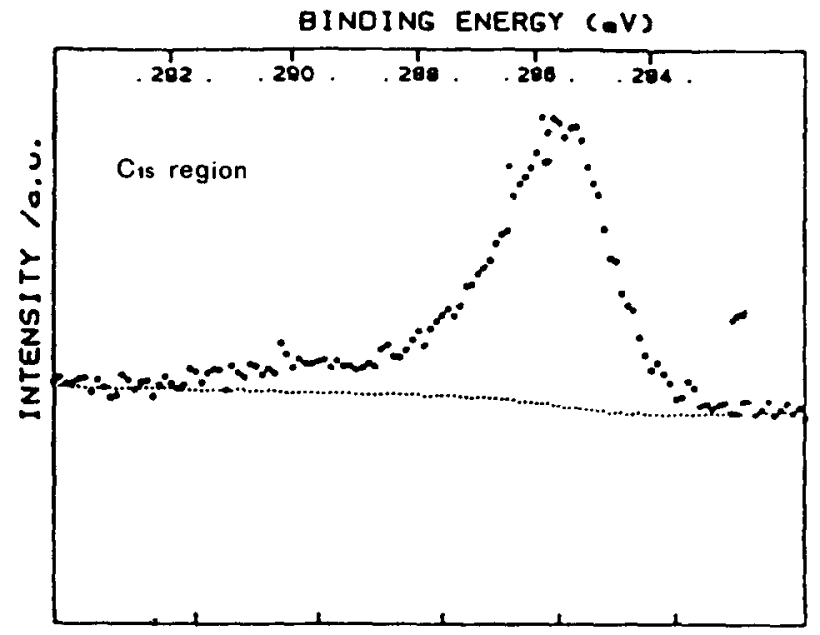

Figure 3. ESCA spectrum of a thin film deposit from anthracene ablation by means of $\mathrm{CO}_{2}$ laser. 


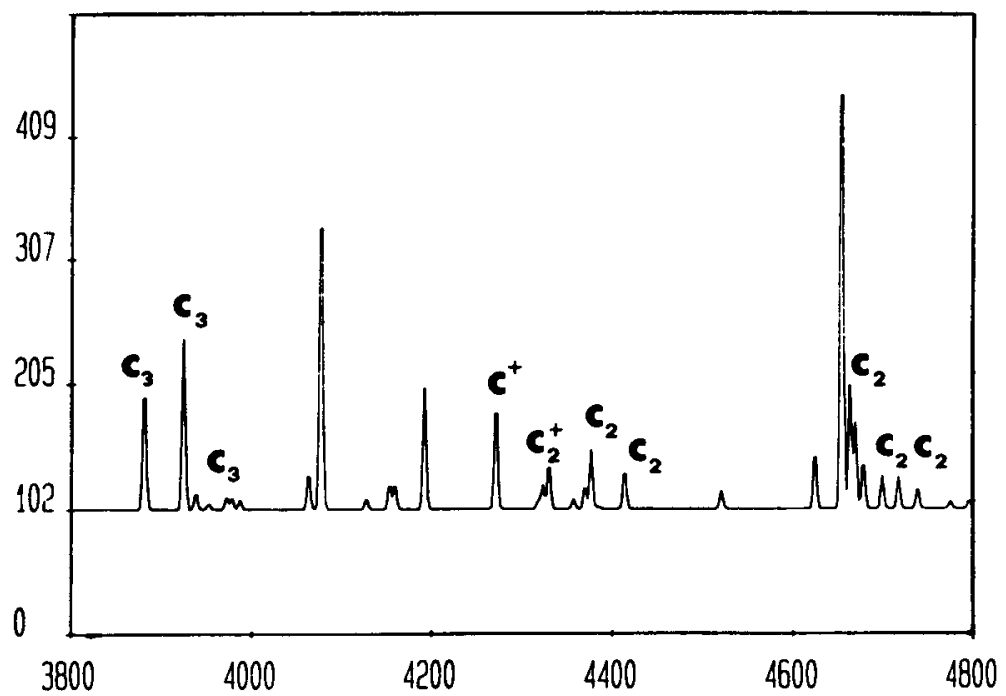

Figure 4. OMA spectral analysis of the plume from anthracene.
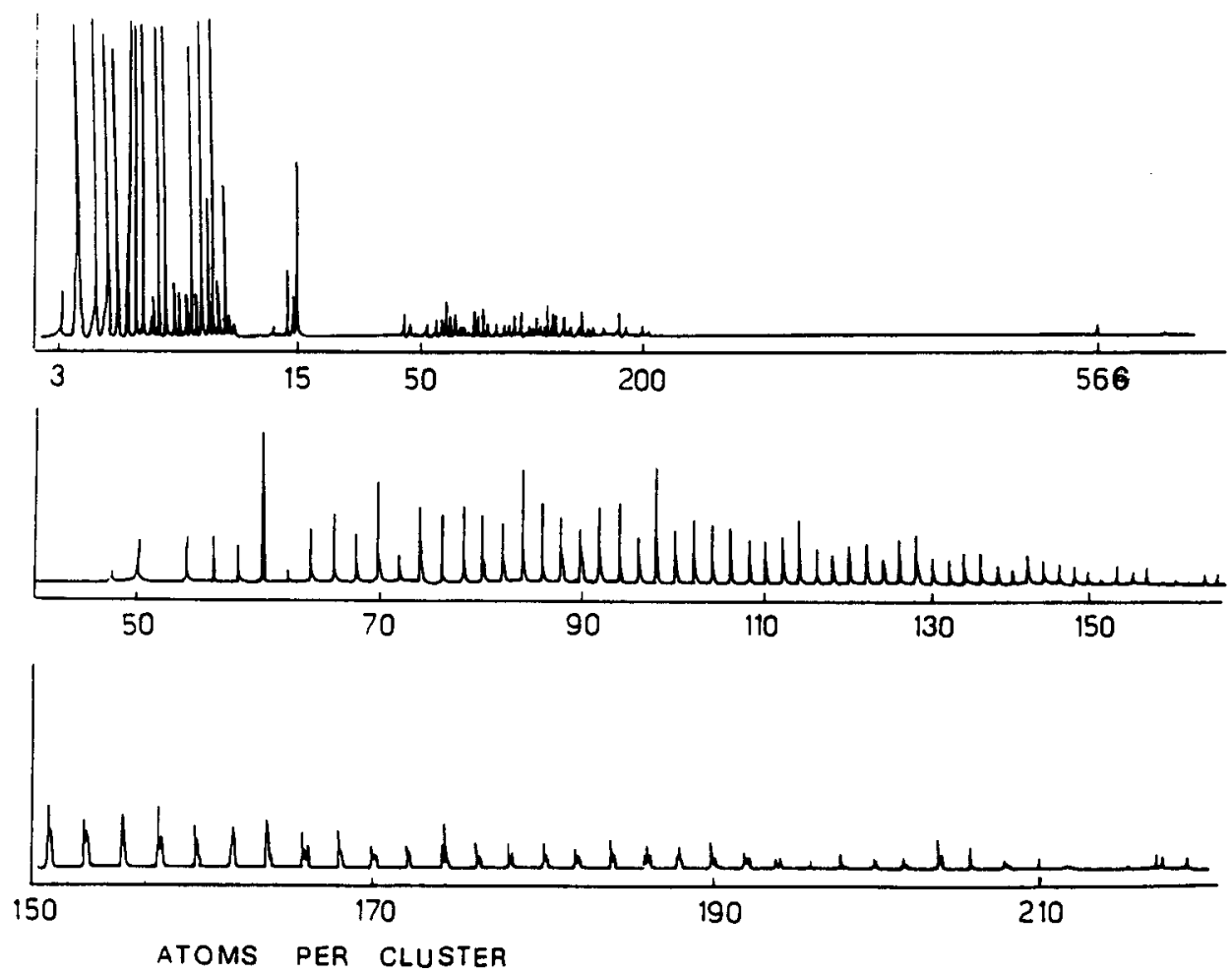

Figure 5. Mass spectra of chrysene.

positive and negative ions is the fact that at masses higher than those corresponding to $\mathrm{C}_{48}$ the spectrum is the same for all the PAH studied (Linemann et al 1989; Mele et al 1989). Similar mass spectra have been observed in laser ablation of pure graphite (Pradel et al 1989). 
In figure 5, the mass spectrum of positive ions observed in chrysene is shown. Although relative intensities depend on experimental conditions, some magic cluster sizes $-\mathrm{C}_{60}, \mathrm{C}_{70}, \mathrm{C}_{84}$ have been observed in agreement with previous data (Rohlfing et al 1984). Recent results on photofragmentation of carbon cluster ions show that in the decomposition process the $\mathrm{C}_{2}$ loss dominates. The negative ion mass spectra indicate the presence of clusterization yielding $C_{n}$ cluster ions up to $n=700$. At mass lower than the parent peak, all the hydrocarbons studied show the presence of $\mathrm{C}_{n}^{-}$, $\mathrm{C}_{n} \mathrm{H}^{-}$.

These results strongly indicate a general tendency of aromatic compounds to produce fragmentation. This is shown from the large number of $\mathrm{C}_{n}^{ \pm}$ions obtained from all hydrocarbons irradiated. The similarity of the aromatic hydrocarbons and of graphite mass spectra supports the hypothesis that ion formation is governed by the same mechanism which produces ablation and chemical reactions in the highly dense cloud of material. Cluster ion formation is, therefore, the ultimate process yielding graphitization. These results are of great relevance in the treatment of wastes of aromatic products. The development of a large-scale plant that uses laser sources may be particularly appropriate for this purpose.

\section{Triazines}

4,6-Aminosubstituted azines are commonly used as herbicides. Their classification depends on the composition of the amino chains (R-NH-) bound to the triazine aromatic ring and on the nature of the other substituent in position 2 , which is usually $-\mathrm{Cl},-\mathrm{O}-\mathrm{CH}_{3}$ or $-\mathrm{S}-\mathrm{CH}_{3}$. In spite of their low toxicity with respect to pesticides, their large use in agriculture makes them major pollutants in the soil and in drinking water sources.

The electronic transitions of these molecules, the $n \rightarrow \pi$ and the $\pi \rightarrow \pi^{*}$, are centred around 272 and $222 \mathrm{~nm}$ respectively in pyridine; the wavelength shifts towards the visible as the molecular complexity increases, e.g. at 323 and $372 \mathrm{~nm}$ in pyrazine (Tomer et al 1988). Photoablation experiments on solid aminotriazines either under vacuum or in the presence of a buffer gas were developed to study the mechanism of decomposition of this important class of pollutants in an attempt to produce non-hazardous species. Laser ablation experiments for optical diagnosis of the plume

Table 1. Solid targets used in laser ablation experiments.

\begin{tabular}{ll}
\hline Common name & \multicolumn{1}{c}{ IUPAC name } \\
\hline Cyanuric acid & 2,4,6-Triazinetriol \\
Melamine & 2,4,6-Triamino-s-triazine \\
& 2-Chloro-4-6-diamino-s-triazine \\
Simazine & 2-Chloro-4,6-bis(ethylamino)-s-triazine \\
Atrazine & 2-Chloro-4-ethylamino-6-isopropylamino-s-triazine \\
Propazine & 2-Chloro-4-6-bis(isopropylamino)-s-triazine \\
Ametryne & 2-Methylthio-4-ethylamino-6-isopropylamino-s-triazine \\
Prometryne & 2-Methylthio-4,6-bis(isopropylamino)-s-triazine \\
Atraton & 2-Methoxy-4-ethylamino-6-isopropylamino-s-triazine \\
& 2,6-Dichloropyrazine \\
\hline
\end{tabular}


from 4,6-aminosubstituted triazines has been performed at $308(\mathrm{XeCl}) \mathrm{nm}$ and $248 \mathrm{~nm}$ (KrF) (Mele et al 1990; Giardini-Guidoni et al 1991). Some simpler systems, belonging to the family of melamines and pyrazines, have been also irradiated for comparison. The compounds studied are listed in table 1 . The mechanism of photodecomposition has been studied by directly detecting the ions formed by coupling a time-of-flight mass spectrometer with a frequency quadrupled $\mathrm{Nd}$ :YAG laser $(\lambda=266 \mathrm{~nm})$ (Giardini-Guidoni et al 1991).

\subsection{Optical diagnosis}

Laser ablation experiments of solid triazine samples have been carried out under vacuum $\left(10^{-6}\right.$ torr background pressure). A luminous plume, with a bright blue-green emission visible to the unaided eye, is seen in all UV laser ablation experiments. According to a recent classification (Ito et al 1989), the laser energy focussed on the sample $(60 \mathrm{~mJ})$ was in the middle fluence region $\left(4 \times 10^{8} \mathrm{~W} / \mathrm{cm}^{2}\right)$ where absorption occurs both from the solid and the first-vaporized gas. Emission spectra of electronically excited fragments have been detected by an Optical Multichannel Analyser as a function of the delay from the laser pulse at different gate widths ( $\geqslant 100 \mathrm{~ns}$ ). Spaceresolved measurements along the luminescent plume axis have been performed by fine adjustment of focussing and collecting optics. All emission spectra of the plume obtained by ablation of different substituted-azines at the two wavelengths used are quite similar. Several ions, atoms and diatomic molecular fragmems in electronically excited states have been detected. The strongest near-UV visible emission lines are mostly due to $\mathrm{CN}$ (violet system with tail bands, from 350 to $425 \mathrm{~nm}$ ), $\mathrm{C}_{2}$ (Swan's system with high pressure band, from $435 \mathrm{~nm}$ to $565 \mathrm{~nm}$ ), $\mathrm{CH}$ (4300 A system, around $431 \mathrm{~nm}$ ), NH ( $3350 \mathrm{~A}$ system, around $336 \mathrm{~nm}$ ), $\mathrm{H}$ (Balmer series) and $\mathrm{C}^{+}$(at $426.7 \mathrm{~nm}$ ). Overview spectra at $308 \mathrm{~nm}$, showing the most intense fragment bands, are shown in figure 6. In ametryne and prometryne atomic sulphur emission appears near $420 \mathrm{~nm}$. In atraton atomic oxygen emission has been detected at $394.73 \mathrm{~nm}$. Weak atomic chlorine lines have been observed in all the chlorinated samples near $481 \mathrm{~nm}$. The intense $\mathrm{CN}^{+}$band around $320 \mathrm{~nm}$ (3185 A system at 326.33 and $318.51 \mathrm{~nm}$ ) has been observed at short time delay in laser ablation of 2,6-dichloropyrazine, which conversely

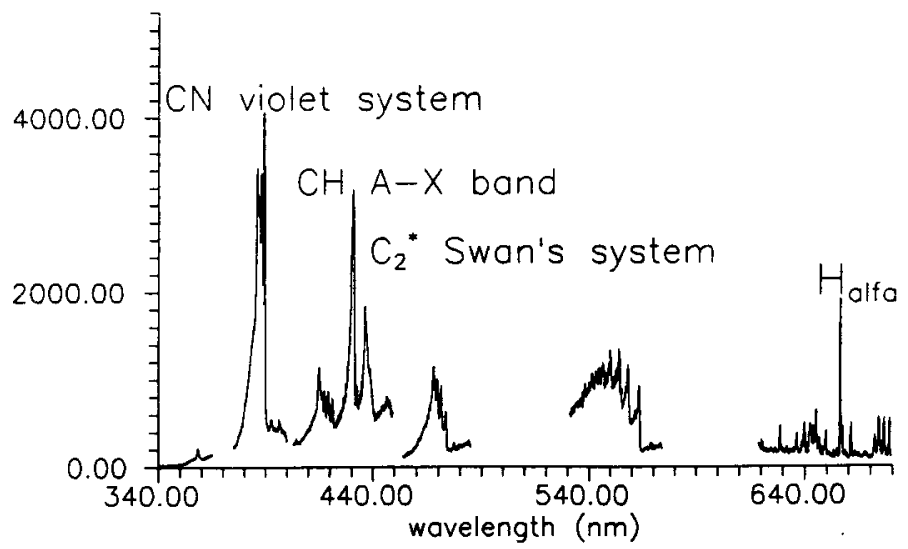

Figure 6. Overview spectrum (most intense portion) during atrazine laser ablation at $308 \mathrm{~nm}$ $(d=2 \mathrm{~mm})$, no gate. 

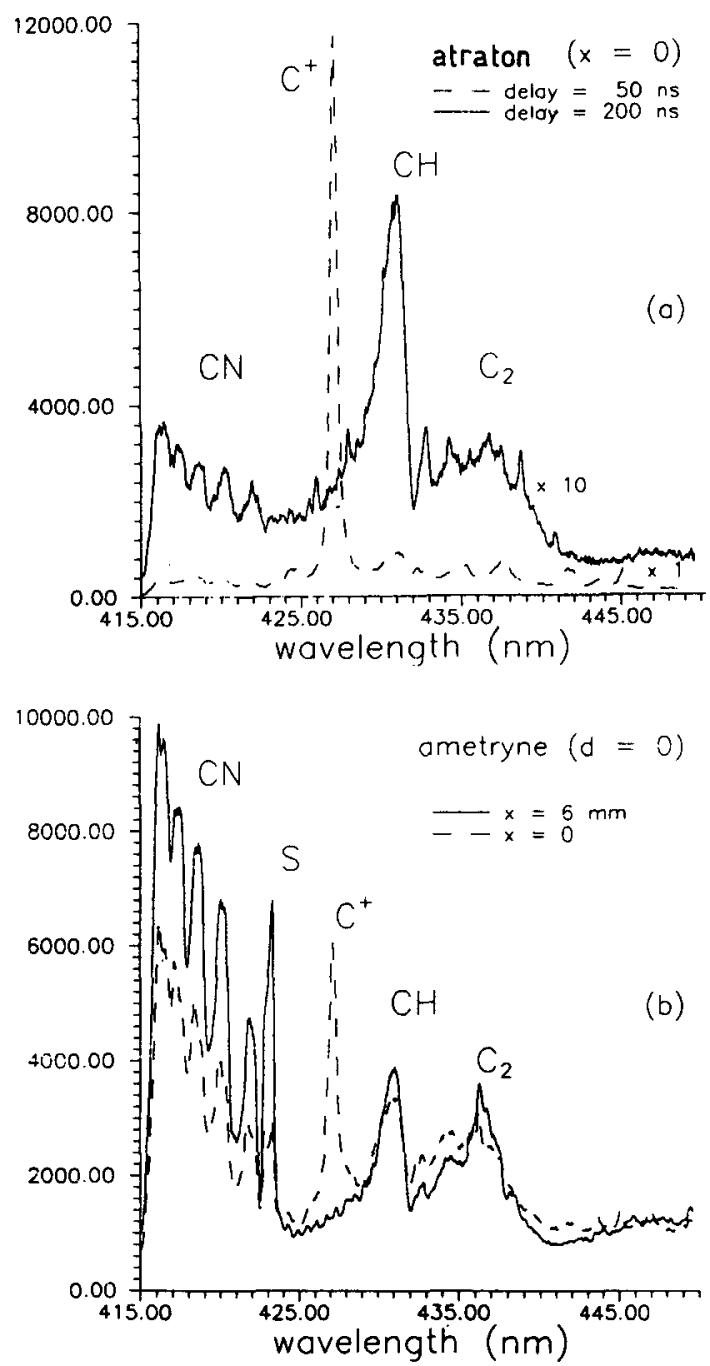

Figure 7. Selected portions of optical emission spectra during laser ablation of different substituted triazines at $308 \mathrm{~nm}$ : (a) Atraton, spectra measured at different delay times from the laser pulse (100 ns gate); (b) Ametryne, spectra measured at different focal distances from the surface (no gate).

did not show any $\mathrm{CH}$ emission. Highly excited atoms and 1ons are detected very close to the ablated surface and at very short time delay with respect to the laser pulse. Their lifetime, monitored by $100 \mathrm{~ns}$ time resolution, appears to be unaffected by the addition of a buffer gas. Emission from highly excited atomic fragments, however, tend to be localised closer to the sample surface as the buffer pressure is increased. Emission from excited molecular fragments comes later in time and is more diffuse in space, as shown by the typical results obtained (figure 7), where significant portions of emission spectra of atraton (a) and ametryne (b) are reported as functions of time delay from the laser pulse and of the focal distance from the surface, respectively. The relaxation of small fragments $\left(\mathrm{CH}^{+}\right)$is observed at the plume border, 

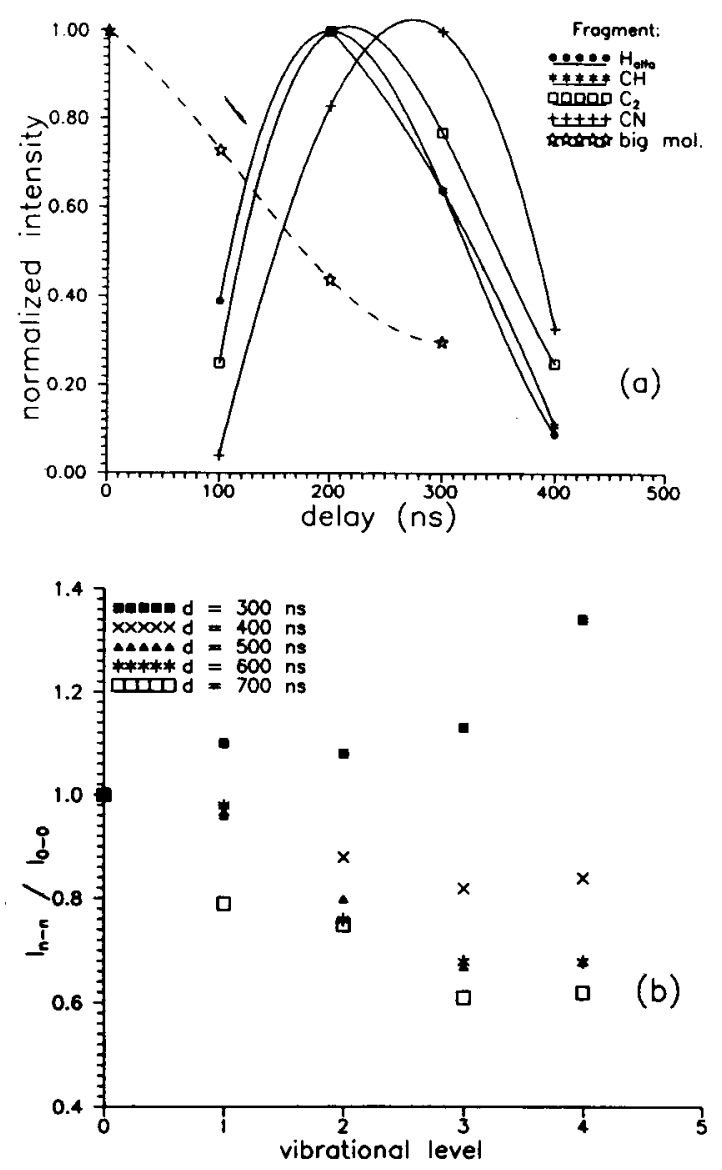

Figure 8. Time evolution of fragment emission during laser ablation of propazine at $248 \mathrm{~nm}$, gate width $=100 \mathrm{~ns}$. (a) Integrated band intensity for different fragments; ablation $2 \mathrm{~mm}$ from the surface, no buffer. (b) Relative intensity of $v-v=0$ emission lines detected in the violet system; ablation at the surface, 10 torr $\mathrm{N}_{2}$ added.

and it has been found that this takes place also upon addition of a buffer gas. A typical time-resolved fragment distribution obtained by laser ablation of propazine at $248 \mathrm{~nm}$ is shown in figure $8 \mathrm{a}$. The vibrational distribution of most abundant electronically excited molecular fragments detected in emission, e.g. CN (violet band), $\mathrm{C}_{2}$ (Swan's system) and $\mathrm{CH}(\mathrm{A}-\mathrm{X}$ band), gives indications of preferential reaction patterns and of secondary fragmentation. Details of the time behaviour of $\mathrm{CN}$ emission in different vibrationally excited levels are reported in figure $8 \mathrm{~b}$. In the case of $\mathrm{N}_{2}$ addition to propazine (10,30 and 80 torr), $\mathrm{CH}$ emission disappears and $\mathrm{H}$ is observed only very close to the surface. Duration of emission from other molecules and delay for maximum fluorescence intensity increase with buffer pressure.

\subsection{Mass spectrometric analysis}

The ionic species produced by laser ablation of solid triazine were mass analyzed by a time-of-flight mass spectrometer. The apparatus and procedure have been previously 

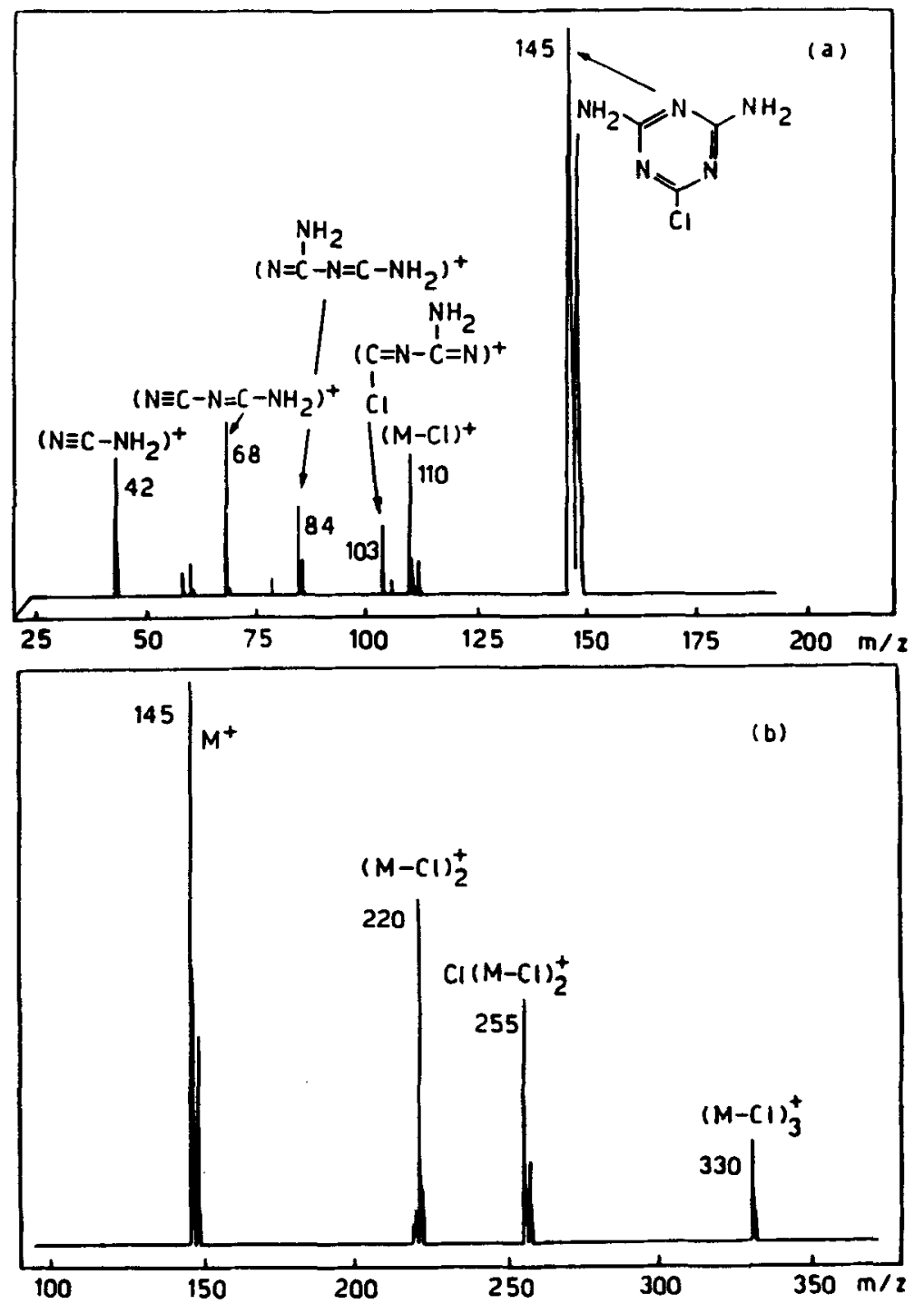

Figure 9. Positive ion mass spectrum of 24chloro-4,6-diamino-s-triazine: (a) fragmentation mass spectrum; (b) cluster ion formation.

described (Mele et al 1992). The solid samples were preparedfrom ground powders, spread on a grid and directly irradiated by a pulsed-frequency quadrupled Nd:YAG laser $(\lambda=266 \mathrm{~nm})$. Both positive and negative ions have been detected and identified.

A typical mass spectrum of a triazine is shown in figure 9: (a) ions at $m / e$ lower than the parent; (b) ions at $m / e$ larger than the parent ion. The ions in figure 9 are produced from fragmentation of the molecular solid. In the higher mass range in figure $9 \mathrm{~b}$, two aggregation processes are identified. Clusters of dehalogenated parent molecules of formula $(\mathrm{M}-\mathrm{Cl})_{n}$ and clusters of chlorine atoms with dehalogenated molecules of formula $\mathrm{Cl}(\mathrm{M}-\mathrm{Cl})_{n}$ are observed. It can be noted from the fragments in figure 9a that a Diels-Alder ring-opening process takes place i.e. a $4+2$ bond rupture occurs. Analogous fragmentation processes are observed for other triazines. 

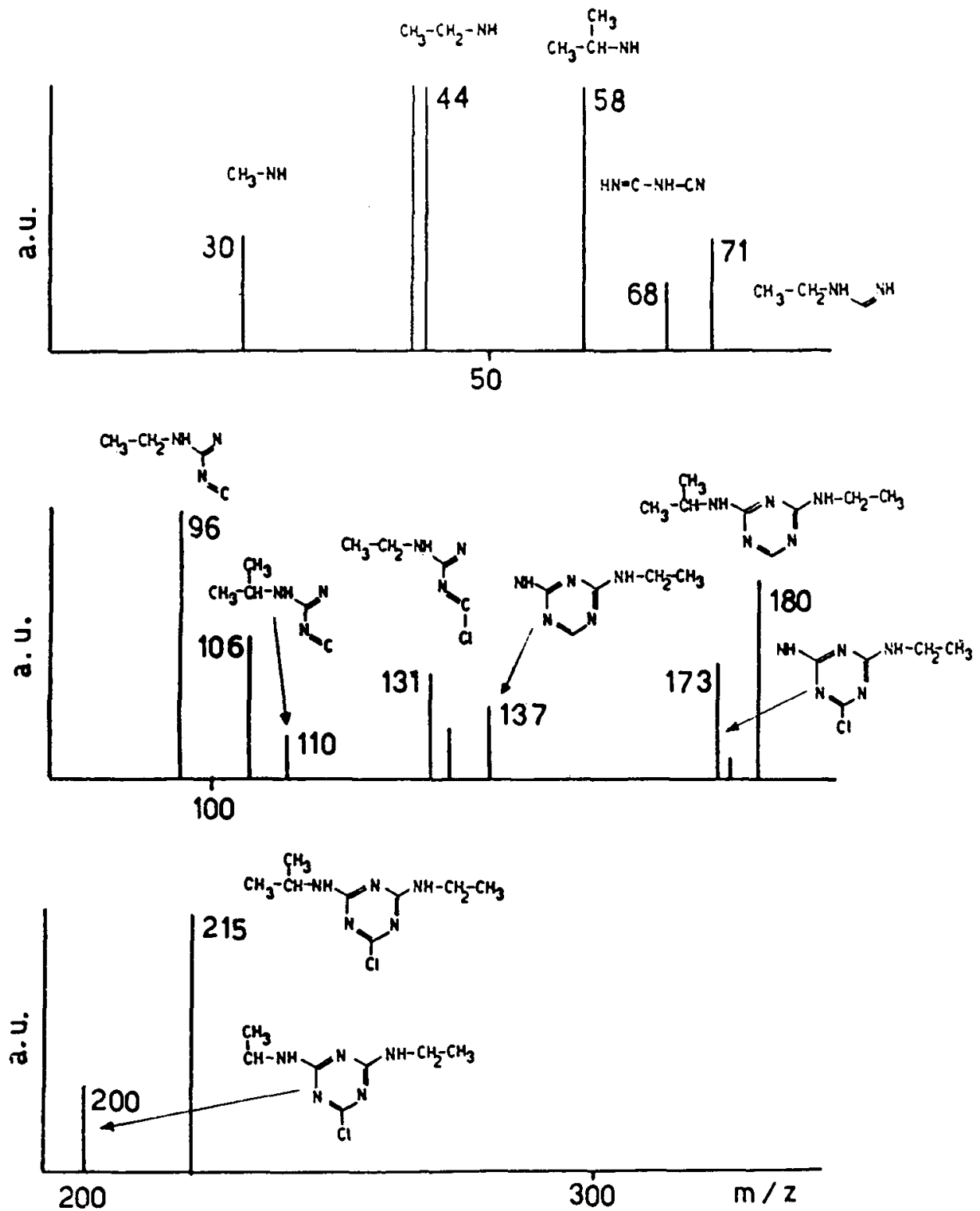

Figure 10. TOF fragmentation mass spectrum of atrazine at $266 \mathrm{~nm}$ : positive ions.<smiles>Nc1nc(N)nc([Si])n1</smiles>

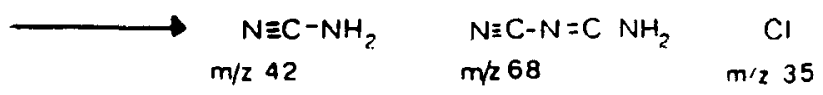
2-chloro-4,6-diamino-s-triazine 
The mass spectra of atrazine in figure 10 shows the various fragments of degradation of the product.

A possible ring opening process is typically the following (Mele et al 1992).

\section{Conclusions}

The results of the present investigation have shown that laser photolysis may be usefully applied to the treatment of dangerous material which has to be rejected. Serious problems have been faced by municipalities in getting rid of substances which can neither be treated by heat nor left in the ground. Among other pollutants PCB are well known as precursors of polychlorodibenzodiaxines (PCDA) and polychlorodibenzofuranes (PCDF) (Eiceman et al 1979). Polycyclic hydrocarbons are also very noxious substances which cannot be easily destroyed. The laser treatment in solution or by laser ablation of the pollutants have shown the effectiveness of the method to obtain non-toxic substances by simple degradation. Investigations have to be made to determine suitable pathways to obtain inert derivatives from such pollutants. Degradation of PCB and PAH has been particularly successful. In both cases, laserinduced decomposition processes lead to very high yields of non-toxic materials: PCB produce low molecular weight compounds; a process of graphitisation takes place by laser irradiation of all PAH examined. The results obtained by ablation of triazines have shown that the laser treatment is not exhaustive. Irradiation leaves behind some amounts of cyanides and polycyanides formed by ring opening and cleavage of triazines. This may be typical of any compound containing the $\mathrm{C}-\mathrm{N}$ bond in its structure. A higher laser fluence will probably provide a more extensive degradation process.

\section{References}

Buser H R 1979 Chemosphere 8415

Dyke S F, Floyd A J, Sainsbury M and Theobald R S 1971 Organic spectroscopy. An introduction. (Harmondsworth: Penguin)

Eiceman G A, Clement E E and Karasek F W 1979 Anal. Chem. 512343

Giardini-Guidoni A, Mele A, Pizzella G, Fantoni R, Lazic V, Moliterni A G G and Snels M 1991a Proc. Int. Conf. Lasers 91821

Giardini-Guidoni A, Mele A, Pizzella G and Teghil R 1991b Org. Mass Spectrosc. 26779

Guggenheim E A and Prue J E 1964 Physicochemical calculation (Amsterdam: North-Holland)

Hrudey S E, Perry R and Willings R A 1974 Environ. Res. 7294

Ito H, Ozaki Y, Suzuki K, Kondow T and Kuchitsy K $1989 \mathrm{~J}$. Mol. Spectrosc. 127283

Linemann D N, Viswanadham S K, Sharkey A G and Hercules D M 1989 Microbeam analysis (ed.) P E Russel (San Franscisco: San Franscisco Press) p. 297

Mele A, Giardini-Guidoni A, Pizzella G, Teghil R and Barbini R 1990 Proc. Int. Conf. on Lasers p. 799

Mele A, Giardini-Guidoni A and Teghil R 1989 Proc. XIV Atomic and Molecular Physics, Riva del Garda, Italy

Mele A, Giardini-Guidoni A, Teghil R, Pizzella G and Letardi T 1992 Mol. Cryst. Liq. Cryst., 219193

Pradel P, Monchicourt P, Lancagne J J, Pedrix M and Watel G 1989 Chem. Phys. Lett. 158412

Rohlfing E A, Cox D M and Kaldor A 1984 J. Chem. Phys. 813322

Tomer J L, Holtzclaw K W, Pratt D W and Spangler L H 1988 J. Chem. Phys. 881528 